\title{
Happiness is when they understand you
}

\author{
Olga Vladimirovna Petrova ${ }^{1^{*}}$ \\ ${ }^{1}$ Linguistics University of Nizhny Novgorod, International Research Laboratory "Theoretical and \\ Applied Issues in Translation Studies", Nizhny Novgorod, Russia
}

\begin{abstract}
Today translation experts agree that a translation teacher should be a practicing translator, aware of modern translation studies, having methodological knowledge and pedagogical skills, including the knowledge of translation didactics. A survey shows that in Russian universities there are practically no teachers with a degree in translation or those who have completed a specialized professional retraining program as a translation teacher. Thus, none of them has the full range of competences required to prepare translators who fully meet the requirements of the current translation industry. To change this situation, it is necessary to develop and implement special programs that allow translation teachers to supplement their education. These programs can be implemented in two formats. Firstly, there can be two different master's degree programs: for those with a bachelor's degree in translation and those with a bachelor's degree in foreign language teaching. The program for the former should include more psychological and pedagogical disciplines, while the program for the latter should focus on translation. Secondly, it can be long-term courses of specialized professional retraining for translation teachers with two different sets of disciplines depending on their degree. Within the above-mentioned programs, special attention should be paid to the course of translation didactics.
\end{abstract}

Keywords: translation teacher, competences, college degree, professional retraining.

\section{Introduction}

The famous phrase of Confucius that happiness is when they understand you, great happiness is when they love you, real happiness is when you love misses one more link. How to determine the degree of happiness of someone who can give another the opportunity to be happy? This is exactly what the translators do. They give people who speak different languages the opportunity to be understood, i.e. to be happy. However, this magic (the ability to make people happy) should be taught. Whether a translator becomes a wizard or not depends on who and how teaches them.

Judging by fairly extensive literature sources, the issue of training translators is quite acute not only in Russia, where they began to prepare translators and interpreters less than thirty years ago, but also in other countries where the demand for translation and translators has been existing for a long time. However, the question of who can teach future translators

*Corresponding author: o.v.petrova/nn@@gmail.com 
and interpreters and what they should know and be able to do has arisen recently. According to M. Orlando, translation was previously taught according to the principle "do as I do", when translators-practitioners simply transferred their experience to the audience [1].

In Russia, this principle was implemented in a slightly different way. In the early 1990s, when the need for translation increased sharply and the number of professional translators was insufficient to meet it, it became necessary to train a large number of translators and interpreters. Because there were few professional translators, foreign language teachers, who often had neither translation training nor practical experience in translating, were brought in to teach the students. Therefore, the principle "do as I do" transformed into "do it like an amateur".

The principle "do as I do" applied not only to translators but also to the next generations of translation teachers. The only thing they could do in class was replicate the way they had once been taught themselves. Some of them also gained practical experience in translation that they shared with their students. In terms of teaching methods, they copied their own teachers. If they were lucky and had been taught by professional translators, then this approach gave good results. If they copied those foreign language teachers who had to become translation teachers (sometimes against their will), the result was the same.

D. Kiraly wrote that a teacher of a foreign language cannot be a good teacher of translation without special training [2]. In the context of the specific situation in Russian universities, the issue is discussed by O.V. Petrova and A.V. Ivanov [3]. Today it is generally accepted that a translation teacher should be a practicing translator, know how to teach translation and be a translation theorist (or, at least, know the main issues and schools of translation studies). These requirements were most clearly formulated by D. Kelly [4] and subsequently supplemented by several other papers $[5,6]$. While there is still debate about whether or not a translation teacher must be engaged in research, the necessity to be a practicing translator and a trained teacher is not doubted by anybody today. For example, in their paper on teaching translation in Serbia, N. Pavlović and G. Antunović refer to a number of works that emphasize the importance of pedagogical excellence on the part of a translation teacher [7: 1-2]. The article by V. V. Sdobnikov, R. M. Shamilov, and D. N. Shlepnev [8] is indicative in this respect. The authors say that along with translation competence, a translation teacher also needs didactic competences of two types: general didactic competence and special didactic competence. The acquisition of these competences calls for special training, both in translation and in methods of teaching.

What is the current situation in Russia in this respect?

\section{$2 \quad$ Methods}

To answer this question, a group of scholars from the Higher School of Translation and Interpreting of Nizhny Novgorod Dobrolyubov State Linguistic University conducted a survey of translation teachers from different universities. In total, 118 respondents participated in the study. The survey had several objectives. First of all, it was necessary to find out what age groups of teachers are currently training translators and interpreters. Since there are many foreign language teachers who once had to start teaching translation, it was necessary to identify the percentage of such teachers still working at universities. In addition, it was necessary to find out how many teachers had taken specialized professional retraining courses and professional development courses over the years.

To obtain this and other information necessary for outlining a Russian translation teacher's profile, the respondents were asked several questions concerning their university education, specialized retraining, age group, teaching experience, translation activities, types of translation and forms of classes they teach, etc. 


\section{$3 \quad$ Results}

Analysis of the answers has shown that $36.5 \%$ of translation teachers are in the age group over 50 , with $13.6 \%$ of the total number of respondents being over 60 . The smallest number of teachers $(9.3 \%)$ is in the group of 22 to 30 . Calculations with the additional parameter of education showed that only $6.3 \%$ of those with a translation degree are over 60 , while $18.8 \%$ are in the 50 to 60 age group. Young teachers (from 22 to 30 years old) with a translation degree amount to $12.5 \%$. Among the teachers with no degree in translation, the pattern is exactly the opposite: the smallest number (5.5\%) fall into the group from 22 to 30 ; their number increases in the older age groups $(27.8 \%$ in the group from 50 to 60 and $22.2 \%$ in the age group over 60).

The correlation between teaching experience and experience in practical translation, as well as the respondents' comments to this effect, indicate that some teachers of the older age groups do not engage in practical translation or identify it with the translation done during their classes. There is one more important indicator: out of 54 respondents who give lectures in translation theory, only 31 have a degree in translation.

Finally, only $9.3 \%$ of the respondents completed specialized retraining courses. Thus, $90.7 \%$ of translation teachers were not trained to teach translation at all. $75.4 \%$ of the respondents completed a kind of short-term refresher training, but judging by their comments, these courses were not focused on teaching translation. They included translation classes, foreign language classes for translation students and workshops, i.e. demonstration of classes in some types of translation. None of such courses included translation didactics as a separate discipline.

\section{Discussion}

The above-mentioned survey has proven that there is no system of professional training for translation teachers. Indeed, it is not only the Russian problem [9]. It is a paradox that there are training programs for teachers of biology, chemistry, native and foreign languages, as well as other disciplines. At the same time, translation teachers are not trained anywhere. As a result, there are two categories of teachers: a) with a translation degree and no pedagogical proficiency; b) with a pedagogical degree, proficiency in foreign languages, without a translation degree. And none of them has ever studied the didactics of translation, something that should form the basis of their professional work.

So, what is it that a translation teacher should be taught? Translation, of course. Moreover, it is not enough for a translation teacher just to know how to translate and be a practicing translator. They should know the translation industry from the inside. D. Gouadec believes that a translation teacher should work for at least a month a) in a translation firm (either as a translator or a reviser or a terminologist); $b$ in an in-house translation service; c) as a freelance professional [5, p. 13]. Such teachers should be aware of all the problems of the industry, the changing requirements and demands of employers, be familiar with the impact of new technologies, their advantages and disadvantages $[10 ; 11]$.

At the same time, as D. Kelly writes, to be a teacher of translation, professional translation experience alone is not enough [12, p. 102]. It is necessary to be aware of new trends, new approaches to translation and problems arising in this context $[13 ; 14]$. This means that even if a teacher should not necessarily be a researcher, as D. Kelly insists, then at least they should have a good knowledge of modern translation studies.

However, this is not enough either. Regardless of the subject he or she teaches, a teacher should be a professional educator. It is not sufficient to "share one's experience", it is necessary to be versed in psychological and pedagogical foundations of this profession. As J. Orchard and K. Winch rightly put it, teachers must understand what they are doing, what 
is the purpose of doing it, why they are doing it in this particular way and be able to think about how to do it better [15]. It agrees with concepts and principles of general didactics and especially of translation didactics.

To become a translation teacher, a person needs to be taught all these things. In other words, there is a need for special training programs. It seems that the most convenient format would be a master's degree with two different programs: for bachelors in translation and bachelors in teaching foreign languages. In the first case, the program should comprise psychological and pedagogical disciplines (including general didactics). In the second case, the program should focus on translation and translation studies. The didactics of translation should be a compulsory discipline in both programs. Besides, the programs should include a period of internship, both in translation and in teaching.

However, this is the way to prepare translation teachers for the future. As for the existing army of translation teachers with one-sided, so to speak, professional training, it is necessary to develop retraining programs of at least 350 hours, structured along the same lines as master's programs. These should be programs implemented (at least in terms of translation and translation didactics) in the format of in-person or online classes - but not via correspondence! Such programs will supplement the missing part of the required professional education.

\section{Conclusion}

Anyone can be happy in their professional life only if they have the full range of competences necessary for this activity. Only in this case translation teachers will be able to ensure that students understand them and learn to make happy those for whom they work. Thus, we have added one more link to the definition of degrees of happiness: a teacher is happy when they are understood by future translators, who, in their turn, will experience happiness at the opportunity to make people happy, because with their help they will understand each other.

\section{Acknowledgments}

The study was supported by the Russian Foundation for Basic Research within the framework of scientific project No. 20-013-00149.

\section{References}

1. M. Orlando, The Interpreter and Translator Trainer, 13(3), 216-232 (2019). https://doi.org/10.1080/1750399X.2019.1656407

2. D. Kiraly, Pathways to Translation. Pedagogy and Process (Kent State University Press, Kent (Ohio), 1995)

3. O. Petrova, A. Ivanov, EpSBS 86, 1075-1084 (2020). https://doi.org/10.15405/epsbs.2020.08.125

4. D. Kelly, A Handbook for Translator Trainers: A Guide to Reflective Practice (St. Jerome, Manchester, 2005)

5. D. Gouadec, Notes on translator-training (replies to a questionnaire), in A. Pym, C. Fallada, J. R. Biau, J. Orenstein (Eds.), Innovation \& E-Learning in Translator Training, in Intercultural Studies Group (Universitat Rovira i Virgili, Tarragona, 2003)

6. The EMT Translator Trainer Profile. Competences of the Trainer of Translation, Version 12 (2013). Accessed on: January 10, 2020. [Online]. Available: 
http://docplayer.net/14445272-The-emt-translator-trainer-profile-competences-of-thetrainer-in-translation.html

7. N. Pavlović, G. Antunović, inTRAlinea, Special Issue: New Insights into Translator Training (2019). Accessed on: October 12, 2020. [Online]. Available: https://www.intralinea.org/index.php/specials/article/2423

8. V.V. Sdobnikov, R.M. Shamilov, D.N. Shlepnev, European Publisher, 86, 1227-1236 (2020). https://doi.org/10.15405/epsbs.2020.08.141

9. C. Bnini, Didactics of Translation. Text in Context (Cambridge Scholars Publishing, Cambridge, 2016)

10. Y. Gambier, Russian Journal of Linguistics, 23(2), 344-361 (2019). https://doi.org/10.22363/2312-9182-2019-23-2-344-361.

11. I. Ovchinnikova, Russian Journal of Linguistics, 23(2), 544-561 (2019). https://doi.org/10.22363/2312-9182-2019-23-2-544-561.

12. D. Kelly, TTR: Traduction, Terminologie, Rédaction, 21(1), 99-125 (2008).

13. V.V. Sdobnikov, Russian Journal of Linguistics, 23(2), 295-327 (2019). https://doi.org/10.22363/2312-9182-2019-23-2-295-327.

14. M. Novikova, Russian Journal of Linguistics, 23(2), 562-568 (2019). https://doi.org/10.22363/2312-9182-2019-23-2-562-568.

15. J. Orchard, C. Winch, IMPACT. Philosophical Perspectives on Education Policies, 22, 2-40 (2015). https://doi.org/10.1111/2048-416X.2015.12002.x 